\title{
In situ chemical fixation of arsenic-contaminated soils: An experimental study
}

\author{
Li Yang, Rona J. Donahoe, James C. Redwine \\ Lawrence Berkeley National Laboratory, 1 cyclotron road, Berkeley, CA 94720, USA \\ Department of Geological Sciences, University of Alabama, Tuscaloosa, AL 35487, USA \\ Southern Company Environmental Services, Birmingham, AL 35401, USA
}

\begin{abstract}
This paper reports the results of an experimental study testing a low-cost in situ chemical fixation method designed to reclaim arsenic-contaminated subsurface soils. Subsurface soils from several industrial sites in southeastern U.S. were contaminated with arsenic through heavy application of herbicide containing arsenic trioxide. The mean concentrations of environmentally available arsenic in soils collected from the two study sites, FW and BH, are $325 \mathrm{mg} / \mathrm{kg}$ and $900 \mathrm{mg} / \mathrm{kg}$, respectively. The soils are sandy loams with varying mineralogical and organic contents. The previous study [Yang L, Donahoe RJ. The form, distribution and mobility of arsenic in soils contaminated by arsenic trioxide, at sites in Southeast USA. Appl Geochem 2007;22:320-341] indicated that a large portion of the arsenic in both soils is associated with amorphous aluminum and iron oxyhydroxides and shows very slow release against leaching by synthetic precipitation. The soil's amorphous aluminum and iron oxyhydroxides content was found to have the most significant effect on its ability to retain arsenic. Based on this observation, contaminated soils were reacted with different treatment solutions in an effort to promote the formation of insoluble arsenic-bearing phases and thereby decrease the leachability of arsenic. Ferrous sulfate, potassium permanganate and calcium carbonate were used as the reagents for the chemical fixation solutions evaluated in three sets of batch experiments: (1) FeSO4; (2) FeSO4 and KMnO4; (3) FeSO4, KMnO4 and $\mathrm{CaCO} 3$. The optimum treatment solutions for each soil were identified based on the mobility of arsenic during sequential leaching of treated and untreated soils using the fluids described in EPA Method 1311 [USEPA. Method 1311: toxicity characteristic leaching procedure. Test methods for evaluating solid waste, physical/chemical methods. 3rd ed. Washington, DC: U.S. Environmental Protection Agency, Office of Solid Waste. U.S. Government Printing Office; 1992] toxic characteristics leaching procedure (TCLP) and EPA Method 1312 [USEPA. Method 1312: synthetic precipitation leaching procedure. Test methods for evaluating solid waste, physical/chemical methods. 3rd ed. Washington, DC: U.S. Environmental Protection Agency, Office of Solid Waste. U.S. Government Printing Office; 1994] synthetic precipitation leaching procedure (SPLP). Both FW and BH soils showed significant decreases in arsenic leachability for all three treatment solutions, compared to untreated soil. While soils treated with solution (3) showed the best results with subsequent TCLP sequential leaching, SPLP sequential leaching of treated soils indicated that lowest arsenic mobility was obtained using treatment solution (1). Treatment solution (1) with only FeSO4 is considered the best choice for remediation of arseniccontaminated soil because SPLP sequential leaching better simulates natural weathering. Analysis of treated soils produced no evidence of newly-formed arsenic-bearing phases in either soil after treatment. Sequential chemical extractions of treated soils indicate that surface complexation of arsenic on ferric hydroxide is the major mechanism for the fixation process.
\end{abstract}

Keywords: In situ chemical fixation (ISCF); Arsenic; Sequential leaching; TCLP; SPLP; Sequential chemical extraction procedure (SCEP) 


\section{Introduction}

Arsenic is an element that is widely distributed in the earth's crust. It ranks twentieth among the elements in abundance in the earth's crust and is a major constituent of no fewer than 245 mineral species (Cullen and Reimer, 1989). Despite of its universal presence, arsenic has been recognized as a well-known toxicant since ancient times. Even at low concentrations, long-term exposure to inorganic arsenic can lead to a series of diseases, including skin tumors, liver dysfunction, gangrene and hearing defect (Hutton, 1987). Both the International Agency for Research on Cancer (IARC) and the Department of Health and Human Services (DHHS) in U.S. have classified inorganic arsenic as a known human carcinogen (ATSDR, 2000).With the further study of arsenic carcinogenic risk, U.S. Environmental Protection Agency (USEPA) has lowered the currentmaximumcontaminant level (MCL) of arsenic in drinking water from $50 \mathrm{ppb}$ to $10 \mathrm{ppb}$ effective January 23, 2006 (USEPA, 2001). The average concentration of arsenic in crustal rock is $2-3 \mathrm{mg} / \mathrm{kg}$ (Tanaka, 1988). The concentration of arsenic in soil is generally higher than that in crustal rock, with the average of about $5 \mathrm{mg} / \mathrm{kg}$ in uncontaminated soils (Peterson et al., 1981). Background concentrations of arsenic in U.S. soils range from less than 1 to $97 \mathrm{mg} / \mathrm{kg}$ depending on regional geology, with an average of about 5 to $7 \mathrm{mg} / \mathrm{kg}$ (Shacklette and Boerngen, 1984; Dragun and Chiasson, 1991). Besides regional geological factor, anthropogenic activities such as nonferrous metal mining and smelting, coal combustion, and widespread application of arsenic-containing compounds such as herbicides, desiccants, andwood preservatives have resulted in contaminations of high local concentrations of arsenic in soils (ATSDR, 2000). Since dissolved arsenic poses a serious health risk upon exposure, leaching of arsenic from contaminated soils into groundwater is a major environmental concern and usually the focus of further remediation efforts.

Subsurface soils from many sites associated with the electrical power industry in North America are contaminated with arsenic because of the heavy application of herbicides containing arsenic trioxide. Major technologies currently used for remediation of heavy-metal contaminated soils include excavation and disposal, vitrification, ectrokinetic treatment, soil flushing and solidification/stabilization. Excavation and disposal is the most direct way to remediate heavily contaminated soils. However, its applicability varies depending on the characteristics of the contaminated site and the remediation process can be very costly, especially if hand digging is required. Vitrification involves high temperature treatment of soil and is aimed primarily at reducing the mobility of metals by their incorporation into a chemically durable, leach resistant, vitreous mass. Because of the difficulties encountered in controlling and treating the volatile emissions produced during this process, its applicability varies from site to site. In addition, vitrification is not cost-effective compared with other remediation methods.

Electrokinetic remediation can be used as an in situ remediation technology, and has been studied by several researchers (Pamukcu and Wittle, 1992; Probstein and Hicks, 1993; Shapiro and Probstein, 1993). The treatment process involves passing a low amperage electrical current between a series of cathodes and anodes imbedded in the contaminated soil. This remediation technology requires the presence of a conducting pore fluid in the soil mass to be treated and is therefore generally applicable to soils only under saturated conditions. Moreover, the contaminated species must be solubilized by the introduction of acids or other appropriate chemicals during the treatment process in order for this remediation technique to be successful (Acar and Gale, 1995; Mulligan et al., 2001a). Soil flushing is another remediation technology designed to solubilize and extract contaminants in soils by extracting aqueous solutions. Additives can be added into extracting solutions to enhance efficiencies. However, this remediation technology mainly focuses on volatile organic compounds and is still quite limited for metal removal (Mulligan et al., 2001b). Arsenic is known to be very recalcitrant for soil flushing with water (Kuhlmeier, 1996; 1997). Although there are chelating agents that can extract arsenic effectively (Peters et al., 1994) and can be used as the additive in soil flushing remediation, the applicability and effectiveness of this remediation technology is still unproven given the extensiveness of the contaminated sites.

Another remediation technology currently being used is solidification/stabilization. This treatment method involves mixing contaminated soils or residual particulates from other treatment methods with a 
physical binding agent to form a crystalline, glassy, or polymeric framework surrounding the waste particles. Coupled with micro-encapsulation, appropriate chemical additives may also be used to convert the contaminants to a solid compound and thus further improve the waste's resistance to leaching. This type of remediation can be performed either in situ or ex situ but typically requires excavation of contaminated soils with large machinery.

The contaminated industrial sites in this study contain large volumes of contaminated soil having low-tomoderate arsenic concentrations in vadose zone, and also contain dangerous high voltage equipment. The traditional remediation technologies (excavation and disposal, vitrification, solidification/stabilization) require excavation of contaminated soils using heavy equipment, which is impossible to perform safely at these sites. Electrokinetic remediation were previously attempted as in situ treatment methods at these sites, but showed very limited success during field-scale demonstration tests (Personal communication, James C. Redwine, Southern Company Services, Inc., 2004).

In cooperationwith our industrial partners, a new in situ chemical fixation (ISCF) remediation technology was developed to safely and economically treat the contaminated area. The ISCF treatment was tailored to the soil chemistry of the contaminated sites and designed to promote the formation of more insoluble arsenic-bearing phases by injections of chemical reagents in order to reduce arsenic environmental leachability. This paper reports an experimental study on ISCF treatment of representative soils from two contaminated sites.

\section{Experimental}

\subsection{Contaminated soil characterizations}

Two representative contaminated sites, FW and $\mathrm{BH}$, were selected for evaluation of in situ chemical fixation as a remediation technology. Both sites are located near the Gulf Coast in the southeastern United States. The soils at these sites are contaminated with arsenic due to the heavy application of herbicide containing arsenic trioxide with a trade name "Anaconda" from former Anaconda smelter as a major ingredient during the 1950s and 1960s. The background concentration of arsenic for soils in the study site areas is less than $3 \mathrm{mg} / \mathrm{kg}$. However, the previous study (Yang and Donahoe, 2007) found environmentally available arsenic concentrations of $325 \mathrm{mg} / \mathrm{kg}$ and $900 \mathrm{mg} / \mathrm{kg}$ as determined by EPA method 3051, respectively, in contaminated soils at the FWand $\mathrm{BH}$ sites.

Soils in the study areas are mainly derived from Quaternary undifferentiated terrace marine and fluvial sediment deposits. There are four major hydrogeologic units for the both sites: unconfined sand aquifer, a silty peat semi-confining bed, a semi-confined sand aquifer and a silt/clay confining unit. A previous soil contamination assessment of the site indicated that arsenic contamination is mainly concentrated in the vadose zone above the surficial sand-and-gravel aquifer (Personal communication, JamesC. Redwine, Southern Company Services, Inc., 2004). Contaminated soil samples were collected from each site at depths of $10 \mathrm{~cm}$ to $60 \mathrm{~cm}$ below the surface with $20 \mathrm{~cm}$ intervals. The samples were placed in 201 plastic buckets, sealed tightly with lids and duct tape and placed inside the cooler with ice packs for immediate transport to the laboratory. Two buckets of representative soil were collected for each site. The collected samples were stored in the sealed container in the lab refrigerator at $4{ }^{\circ} \mathrm{C}$ before further analysis.

A portion of the soil samples from each site was placed in an oven at $60{ }^{\circ} \mathrm{C}$ for gravimetric $\%$ moisture determination. The remaining soil sample was thoroughly homogenized by hand and passed through a $1 \mathrm{mmsieve}$ for use in chemical fixation experiments. Soils from both sites are fine to medium unconsolidated sandy loams with quartz as their major mineral component and varying amounts of organic matter. $\mathrm{BH}$ soil has a higher arsenic content $(900 \mathrm{mg} / \mathrm{kg})$ than $\mathrm{FW}$ soil $(325 \mathrm{mg} / \mathrm{kg})$, as determined by microwave-assisted nitric acid digestion (EPA Method 3051; USEPA, 1994b). Detailed soil characterization methods are reported elsewhere (Yang andDonahoe, 2007). Soil properties for both study sites are listed in Table 1. 


\subsection{In situ chemical fixation batch experiment}

It is known that partitioning of arsenic between solution and sediments in aqueous systems is often closely associated with the cycling of iron (Belzile and Tessier, 1990; Sakata, 1987; Elkhatib et al., 1984). Furthermore, ferric ion has been used as an effective coagulation reagent in the treatment of arseniccontaminated wastewater (Cheng et al., 1994; Edwards, 1994; Hering et al., 1996). A study by Krause and Ettel (1988) showed that arsenic can form relatively insoluble ferric iron compounds, which have solubility products on the order of 10-20 to 10-24.

After a literature search, ferrous sulfate was chosen as the major ingredient of chemical fixation solutions to be evaluated in this study for treatment of arsenic-contaminated soil. Because arsenic pentavalent compounds are more insoluble, less mobile and therefore less toxic in common Eh-pH conditions found in the environment, potassium permanganate was also added to some of the fixation solutions as an oxidant. Calcium carbonate was added to one fixation solution to buffer the $\mathrm{pH}$. Three different treatment solutions were tested to find the optimal combination for arsenic fixation: (1) ferrous sulfate (FS); (2) ferrous sulfate and potassium permanganate $(\mathrm{FS}+\mathrm{PM})$; (3) ferrous sulfate, calcium carbonate and potassium permanganate $(\mathrm{FS}+\mathrm{PM}+\mathrm{CC})$. The molar ratios of each reagent chemical to total soil arsenic content (determined by EPA method 3051) were chosen as: FeSO4·7H2O: As=2:1, CaCO3:As=4:1, $\mathrm{KMnO} 4: \mathrm{As}=5: 2$.

Batch experiments were conducted in duplicate by reacting $150 \mathrm{~g}$ samples of contaminated soil with each of the treatment solutions in 21 polypropylene bottles. Each experiment was performed at a soil:solution ratio of 0.3 , using 3 days of cure time.

\subsection{Powder XRD and SEM analysis}

The treated soil samples were subjected to powder X-ray diffraction (XRD) analysis using a Philips XRG3100 automated X-ray powder diffractometer $\left(\mathrm{Cu} \mathrm{K \alpha}\right.$ radiation at $45 \mathrm{KVand} 40 \mathrm{~mA}, 2$ to $70^{\circ} 2 \theta$, $0.04^{\circ} 2 \theta$ / s scan speed). Scanning electron microscopy (SEM) analysis was performed on a Philips XL30 scanning electron microscope equipped with an energy-dispersive X-ray (EDX) spectrometer. Both bulk soil and b2 $\mu \mathrm{m}$ clay-sized soil particles separated by flotation according to Stock's Law were carbon coated and analyzed by SEM to detect trace arsenic-bearing phases in the studied soils. Qualitative chemical composition information for the observed soil particles was obtained by EDX analysis. More accurate chemical compositions of any arsenic-bearing particles were determined by electron microprobe analysis (EMPA) using a JEOL 8600 Superprobe equipped with an energy-dispersive spectrometer (EDS) and five wavelength-dispersive spectrometers (WDS).

\subsection{Sequential leaching experiment}

Treated and untreated soils were subjected to sequential leaching using the leachate solutions described in U.S. EPAMethods 1311 and 1312 (USEPA 1992 and 1994a) in order to evaluate the effectiveness of each treatment solution for reducing the mobility of arsenic during long-term leaching. EPA Method 1311 toxicity characteristic leaching procedure (TCLP) fluid is an acetic acid solution with a $\mathrm{pH}$ of 2.88 , while EPA Method 1312 synthetic precipitation leaching procedure (SPLP) fluid is a dilute mixture of sulfuric and nitric acids having a pH of 4.20. One gram samples of homogenized soil and $15 \mathrm{ml}$ of TCLP or SPLP fluid were put into a $20 \mathrm{ml}$ glass vial. The vial was capped and shaken for $24 \mathrm{~h}$ on New Brunswick Innova 2100 platform shaker at $200 \mathrm{rpm}$, then centrifuged for $20 \mathrm{~min}$ at $3000 \mathrm{rpm}$. After centrifugation, the supernatant solution was removed, another $15 \mathrm{ml}$ of the leachate fluid was added to the residue, and the samples were subjected to another $24 \mathrm{~h}$ of leaching. All supernatant leachate solutions were passed through $0.2 \mu \mathrm{m}$ nylon syringe filters, acidified with $2 \%$ Optima ultra-pure HNO3 acid according to the size of sample collected and analyzed for total arsenic by axial view ICP-AES analysis (Perkin Elmer 3000DV). Sequential leaching was continued until the supernatant solution arsenic concentration reached the ICP-AES detection limit $(0.005 \mathrm{mg} / \mathrm{l})$. 


\subsection{Sequential chemical extraction experiment}

Although sequential leaching of treated and untreated soil allows evaluation of the effectiveness of the ISCF treatment solutions, it does not provide any information about the mechanism of arsenic immobilization. A 4-step sequential chemical extraction procedure (SCEP)modified from that of Wenzel et al. (2001) was used to study the change in soil arsenic distribution resulting from chemical fixation treatment of $\mathrm{BH}$ and FW soils. Although the information on phase associations obtained from sequen- tial chemical extractions are usually operationally defined, it is still a very useful tool to assess the association of arsenic with different environment pools after careful selection of extraction reagents and optimization of the extraction procedure. The adopted SCEP is designed to target the arsenic fractions primarily associated with (1) non-specifically sorbed; (2) specifically sorbed; (3) amorphous and poorly-crystalline hydrous iron and aluminum oxides and (4) well-crystallized hydrous oxides of iron and aluminum (Wenzel et al., 2001). Only the soil samples treated with fixation solutions determined by sequential leaching to be the optimal reagent combinations were subjected to sequential chemical extraction.

After centrifugation and removal of as much of the treatment solution as possible, the treated soil sampleswere allowed to air dry. The air-dried samples were gently crushed and thoroughly homogenized for later analysis. A portion of each untreated soil sample was also dried in air to compare with the treated soils. Representative $1 \mathrm{~g}$ samples of the air-dried treated and untreated soils were placed into $50 \mathrm{ml}$ conic polypropylene centrifuge bottles and subsequently subjected to a 4-step sequential chemical extraction procedure following the method developed by Wenzel et al. (2001). The chemical reagent concentrations and volumes of each extraction solution, as well as the conditions and detailed procedures used for each extraction step are listed in Table 2. Duplicate extractions were performed for each soil sample. The extraction samples were shaken at $260 \mathrm{rpm}$ for the specified period of time required by the extraction procedure on a platform shaker. Between each step in the extraction procedure, samples were centrifuged at $3000 \mathrm{rpm}$ for $30 \mathrm{~min}$ before the supernatant solution was withdrawn. The extractant solutions were passed through $0.2 \mu \mathrm{m}$ nylon syringe filters and acidified with $2 \%$ Optima ultra-pure nitric acid. All extractant solution samples were stored in a refrigerator at $4{ }^{\circ} \mathrm{C}$ prior to ICP-AES analysis.

\section{Results}

\subsection{In situ batch fixation experiments}

The chemical compositions of the control and fixation solutions after batch reaction with BH and FW soil are listed in Tables 3 through 5. For all three treatment solutions, some calcium was dissolved during the treatment process. However, no significant amount of arsenic was leached from the soils during treatment for any of the fixation solutions.Comparing the results of the three sets of fixation experiments, it can be seen that fixation solution 2 (FS+PM) had a significantly higher final arsenic concentration than the other two fixation solutions. Batch reactions with fixation solutions 1 (FS) and 3 (FS+PM+ CC) produced much less arsenic in the supernatant solution. However, compared to the total arsenic content of the soils, the amount of arsenic leached during treatment was minimal.

\subsection{Powder XRD and SEM analysis}

Comparison of the powder XRD patterns of the treated and untreated soils shows that there were no detectable changes in the soil mineralogy after in situ chemical fixation treatment. Likewise, SEM and EMPA analyses of treated FWand BH soils also failed to show any obvious differences in trace mineral phases after treatment. However, EDX spectra of many treated soil particles contained large Fe peaks, while untreated soil particles showed little Fe and no arsenic. A few particles were detected in both treated soils which showed associations between Fe and arsenic in EDX spectra collected on certain areas of the particle surfaces. However, the morphologies of these particles don't seem to indicate the formation of any new arsenic-bearing phases. Overall, no newly-formed arsenic-bearing phases were detected in any of the treated soils by any of the available analytical techniques. 


\subsection{Sequential leaching}

In order to better evaluate the long-term leaching behavior of arsenic from FWand BH soils before and after ISCF treatment, the amount of arsenic leached during each sequential leaching step was converted to ppm on a dry weight basis of soil and the percentages of total extractable arsenic thatwere cumulatively leached by SPLP and TCLP sequential leaching were calculated according to the corresponding soil arsenic content, as determined by EPA Method 3051. The percentage of arsenic leached by TCLP and SPLP fluids from untreated soil as well as soil treated with the three different fixation solutions are presented in Figs. 1 (BH soil) and 2 (FW soil). From their TCLP and SPLP cumulative sequential leaching behaviors, it is clearly shown that both of the studied soil samples showed significant reductions in arsenic leachability after treatment with all 3 fixation solutions, compared to untreated soil. However, the effectiveness of each fixation solution varied with soil type and the leachate fluid used.

The percentages of total leachable arsenic removed by SPLP and TCLP fluid from treated FW and BH soil samples compared to untreated soil samples is shown in Fig. 3. Although similar arsenic leaching patterns were observed for both studied soils, the percentage of total leachable arsenic removed from $\mathrm{BH}$ soil was always lower than the percentage of total soil arsenic leached from FW soil, regardless of the treatment solution or leachate fluid used. When subjected to TCLP sequential leaching, both soils showed lowest leachable arsenic after treatment with the fixation solution combination of FS+PM+CC. Compared to the total amount of arsenic removed from untreated soil leached for about the same period of time, only $27 \%$ of the arsenic was leached from FW soil and 13\% from BH soil. Similar TCLP leaching results were seen for these soils after treatment with the FS+PM fixation solution. While treatment with the solution containing only ferrous sulfate produced the worst results, FW and $\mathrm{BH}$ soils showed $56 \%$ and $67 \%$ reductions, respectively, in leachable arsenic, compared to untreated soil.

However, for SPLP sequential leaching, the effectiveness of the treatment solutions showed exactly the reverse trend. Treatment of the soilswith the FS solution resulted in the greatest decreases in leachable arsenic, with $19 \%$ and $16 \%$, respectively, of the arsenic leached from untreated soil being removed from treated FW and $\mathrm{BH}$ soils. The treatment solution containing $\mathrm{FS}+\mathrm{PM}+\mathrm{CC}$ produced the worst results, with $74 \%$ of the leachable arsenic being removed from treated FW soil and $57 \%$ removed from treated BH soil by SPLP sequential leaching. The FS+PM treatment solution had an intermediate effect on arsenic mobility for both soils.

In order to better evaluate the effectiveness of each treatment solution, the cumulative arsenic removed from each treated soil by SPLP sequential leaching was calculated as a percentage of the cumulative arsenic removed from each corresponding treated soil by TCLP sequential leaching for the same total leaching time. Fig. 4 compares the percentages of arsenic leached by SPLP vs. TCLP sequential leaching for each fixation solution treatment and the untreated soils. The data show that SPLP leaching only removed $32 \%$ and $23 \%$ of the total arsenic removed by corresponding TCLP leaching from FW and BH soils, respectively. However, except for the soil samples treated with the FS solution, which have lower percentages of arsenic leached compared to the untreated soils, soil samples treated with the FS+PM and $\mathrm{FS}+\mathrm{PM}+\mathrm{CC}$ solutions all have higher percentages of arsenic removed than the untreated soils.

Compared to treatment with FS only, the above results indicate that the treatments containing PMhave an adverse effect, leaving large portions of the soil arsenic unfixed and vulnerable to SPLP leaching. Although TCLP is the approved standard procedure for characterizing hazardous waste by USEPA, it is mainly designed to evaluate metal mobility in landfill environment and does not represent the leaching conditions encountered in the studied sites, where natural precipitation is the dominant factor. Considering the overall effect of each treatment solution, the FS solution is considered the most effective treatment for leaching conditions expected in the field.

\subsection{Sequential chemical extractions}

Results of the sequential chemical extraction procedure (SCEP) experiments are listed in Tables 6 through 
7. In order to better represent changes in soil element distributions after ISCF treatments, the element concentrations in each extraction solution were converted to the percentage of the total amount removed by all of the extraction steps. Figs. 5 and 6 compare the percentages of arsenic and Fe removed by each extraction step from treated and untreated FWand BH soil samples. The data clearly show that after the soils are treated with the FeSO4 fixation solution, the most labile arsenic fraction, removed from the soil by the first extraction step (S1), was greatly reduced for both of the studied soils. Compared to the untreated soils, the percentage of arsenic removed from the treated soils by the first extraction step was reduced to about one tenth that of the untreated soils. For FW soil, the percentage of arsenic extracted by S1 was reduced from $16 \%$ to $1.78 \%$ after the ISCF treatment; for BH soil, S1 extractable arsenic was reduced from $13.8 \%$ to $0.76 \%$ after the soil treatment.

Another noticeable change in both soils after ISCF treatment was a considerable increase in the percentage of arsenic extracted by the third sequential extraction step (S3). The percentage of arsenic extracted by S3 increased from $37.15 \%$ to $52.48 \%$ for $\mathrm{FW}$ soil and increased from $48.6 \%$ to $71.69 \%$ for $\mathrm{BH}$ soil. These results indicate that most of the labile arsenic in the S1 soil fraction was transferred by ISCF treatment to be associated with phases extracted by S3 of the SCEP.

In addition, ISCF treatment resulted in large increases in the amount of iron extracted by S3, while the percentage of the total iron extracted by the fourth sequential extraction step (S4) of the SCEP was significantly decreased for both $\mathrm{FW}$ and $\mathrm{BH}$ soil. The percentage of total extractable Fe removed by S3 was increased from $33 \%$ to $62 \%$ for $\mathrm{FW}$ soil and from $52.7 \%$ to $86.7 \%$ for $\mathrm{BH}$ soil, while S4 iron decreased from $66.74 \%$ to $35.92 \%$ for $\mathrm{FW}$ soil and from $47.1 \%$ to $12.32 \%$ for $\mathrm{BH}$ soil. There was also a noticeable increase in the percentage of iron extracted with the S1 soil fraction for both of studied soils after the ISCF treatment; however, the S1 iron increases are insignificant compared to the much larger increases and amounts of total iron associated with S3. The third extraction step is designed to attack amorphous aluminum and iron oxyhydroxides in soil samples. The SCEP results therefore strongly suggest that most of the treatment solution Fe formed amorphous iron hydroxide in the studied soils.

\section{Discussion}

The objective of in situ chemical fixation treatment is to inject chemical reagents directly into contaminated soils to favor the formation of more insoluble arsenic-bearing phases. The initial design of the remediation experiments was based on the following possible reactions:

$$
\begin{array}{r}
{ }^{15} \mathrm{AsO}^{3-} 3+{ }^{6} \mathrm{MnO}_{-4}+18 \mathrm{H}+\rightarrow 2 \mathrm{Mn}_{3}\left(\mathrm{AsO}_{4}\right)_{2}+11 \mathrm{AsO}^{3-} 4+9 \mathrm{H}_{2} \mathrm{O}(1) \\
{ }^{3} \mathrm{Fe}^{2+}+\mathrm{MnO}_{4}+4 \mathrm{H}^{+} \rightarrow 3 \mathrm{Fe}^{3+}+\mathrm{MnO}_{2}(\mathrm{c})+2 \mathrm{H}_{2} \mathrm{O}(2) \\
\mathrm{Fe}^{3+}+3 \mathrm{H}_{2} \mathrm{O} \rightarrow \mathrm{Fe}(\mathrm{OH})_{3}+3 \mathrm{H}^{+}(3) \\
4 \mathrm{Fe}^{3+}+2 \mathrm{AsO}^{3-}{ }_{4}+6 \mathrm{H} 2 \mathrm{O} \rightarrow 2 \mathrm{Fe}(\mathrm{OH})_{3}+2 \mathrm{FeAsO}_{4}+6 \mathrm{H}+(4) \\
\equiv \mathrm{FeOH}^{0}+\mathrm{H}_{3} \mathrm{AsO}_{4} \rightarrow \mathrm{FeH}_{2} \mathrm{AsO}_{4}+\mathrm{H}_{2} \mathrm{O}(5) \\
\equiv \mathrm{FeOH}^{0}+\mathrm{H}_{3} \mathrm{AsO}_{3} \rightarrow \mathrm{FeH}_{2} \mathrm{AsO}_{3}+\mathrm{H}_{2} \mathrm{O}(6)
\end{array}
$$

Ferrous sulfatewas used as themajor ingredient of the fixation solutions because of the close association of iron compound with arsenic and the low solubility of ferric arsenate. Potassium permanganate was used in two of the treatment solutions to help oxidize any As(III) in the soil samples into the less toxic and more stable $\mathrm{As}(\mathrm{V})$. Permanganate could also help convert soil arsenic species into Mn3(AsO4)2, which is fairly insoluble. Because of the strongly acidic solution generated by combining ferrous sulfate and potassium permanganate $(\mathrm{pHb} 3)$, calcium carbonate was used as a buffer in one of the treatment solutions.

From the chemistry of the reacted fixation solutions and the corresponding blank test solutions, it is apparent that large amounts of iron and manganese remained in the contaminated soils. The sequential 
leaching experiment results clearly showed that soil arsenic leachability was reduced by as much as $90 \%$ after in situ chemical fixation treatment. However, because no newly-formed arsenic-bearing phases were detected by XRD or by SEM/EDX in the treated soils, the mechanism by which the treatment solution reduces the leachability of soil arsenic could not be conclusively shown.

One possible immobilization mechanism is through the formation of insoluble arsenic-bearing phases by the reactions described in Eqs. (1)-(6), above. It is possible that some insoluble arsenic-bearing phases might have formed during the ISCF treatment process. However, no such phases were detected by either XRD or SEM/EDX analyses, suggesting that if existed, their amounts must be very small (XRD and SEM/EDX detection limit is about 1\%). Moreover, studies by other researchers have indicated that precipitation of $\mathrm{Fe}-\mathrm{As}$ and $\mathrm{Mn}-\mathrm{As}$ phases is very unlikely. The introduction of ferric ions for removal of arsenic from hydrometallurgical processed solutions and in water treatment has been studied by many researchers (Robins et al., 1987; Edwards, 1994; Cheng et al., 1994; Hering et al., 1996). These studies indicated that coagulation and adsorption are the major mechanisms for arsenic removal. Although Robins et al. (1987) referred to the solids formed from solutions containing arsenic and ferric ions as "basic ferric arsenate", later evidence conclusively showed that the precipitated material was in fact not a compound of Fe(III) and As(V), but simply an adsorptive binding of arsenic on ferric hydroxide. Robins et al. (1992) pointed out that ferric arsenate can form only at relatively high concentrations of ferric and $\mathrm{As}(\mathrm{V})$ ions in a low $\mathrm{pH}$ environment.

The ISCF solution containing only ferrous sulfate has a $\mathrm{pH}$ of about 5.4. Assuming that all of the soil arsenic (as determined by EPA Method 3051) was available for reaction with the treatment solution Fe retained by the soil, the calculated ratio of "co-precipitated" Fe:As is about 1:1.2 for FS treatment of both studied soils. Given the relatively high $\mathrm{pH}$ and low ferric and $\mathrm{As}(\mathrm{V})$ ion concentrations of the reacted FS treatment solutions, it is unlikely that ferric arsenate would form during the treatment process.

Ferrous sulfate has been used as a binding agent for the treatment of arsenic-contaminated soils by other researchers (Voigot et al., 1996; Moore et al., 2000); however, these studies also failed to find any evidence of insoluble ferric arsenate being produced. The previous characterization study of untreated FW and $\mathrm{BH}$ soils showed that arsenic was primarily associated with soil particle surfaces, rather than located in individual arsenic-rich grains (Yang and Donahoe, 2007). Arsenic is particle-reactive and therefore more likely to be adsorbed onto amorphous aluminum or iron oxyhydroxides as well as other adsorbent phases in contaminated soils, other than to remain in solution. Given the fact that the soil particles were allowed to thoroughly react with the ferrous sulfate treatment solution, it is more likely that the added ferrous ions hydrolyzed into ferric ions and precipitated as amorphous ferric hydroxide surface coatings on soil particles during the treatment process.

As the result of ISCF treatment,more of the existing soil arsenic became associated with newly-formed iron hydroxide coatings on soil particles. This mechanism for arsenic immobilization is supported by the results of sequential chemical extractions performed on the treated soils (Table 6 and 7), which showed that the injected iron was added to the soil fraction extracted by the third SCEP step. Because this step is designed to target amorphous aluminum and iron oxyhydroxides, the iron added to the soil by the treatment process is shown to exist mainly as amorphous ferric hydroxide. The concurrent increase in the percentage of the total soil arsenic extracted by the third SCEP step further corroborates that ISCF treatment redistributes soil arsenic to be associated with the precipitated amorphous iron hydroxide coatings.

The strong adsorption of arsenic onto poorly-crystalline hydrous iron oxides by surface complexation reactions has been proposed and experimentally verified by many researchers (Waychunas et al., 1993; Manceau 1995; Fendorf et al., 1997; Manning et al., 1998). Comparing the distribution of arsenic and iron in the treated and untreated soils as determined by the SCEP (Fig. 5 and 6), the observed large concurrent increases in arsenic and iron in the $\mathrm{S} 3$ soil fraction indicate that a significant amount of the arsenic in both FWand BH soils was associated with newly-formed amorphous iron hydroxide by the ISCF treatment. It 
is suggested that after treatment with the FS fixation solution, soil arsenic was immobilized by newlyformed hydrous iron oxides through surface complexation reactions. Although the release of heavy metals during transformation of poorly-crystalline hydrous iron oxides into more crystallized phases is still of environmental concern, studies have shown that arsenic surface complexation greatly retards the crystallization rate of poorly-crystalline materials such as ferrihydrite, and that amorphous hydrous iron oxides show greatly enhanced environmental stability after surface complexation by arsenic or other heavy-metal species (Emett and Khoe, 1994; Paige et al., 1997; Ford, 2002).

The SPLP sequential leaching experimental results in Fig. 4 indicated that the treatment solutions containing potassium permanganate had an adverse effect of leaving large portions of arsenic in the treated soils vulnerable to SPLP leaching. Compared to the treatment with ferrous sulfate only, the addition of potassium permanganate will greatly speed the oxidation and precipitation of ferrous ion during treatment process. This rapid precipitation of amorphous ferric hydroxide may not be conducive to the formation of complete iron hydroxide coatings on the contaminated soil particles and hinder their reaction with soil arsenic, which may leave portions of soil arsenic unfixed and vulnerable to SPLP leaching. In addition, it is possible that the highly acidic pHconditions produced with the addition of potassium permanganate reagents may favor the formation of other metastable iron sulfate minerals that have an adverse effect on the soil arsenic fixation process. The treatment solution with ferrous sulfate only is considered the optimal treatment method based on current study. During field application, the rate of hydrolysis of ferrous ion in the treatment solution may need to be optimized to favor the reactions of iron hydroxide coatings with soil arsenic for optimal result.

\section{Conclusions}

Arsenic-contaminated soils from two industrial sites were successfully treated with an in situ chemical fixation remediation method. Three different treatment solutions: FS, FS+PM and FS+PM+CC, were tested to find the optimal treatment solution composition. All treatment solutions were found to be effective for both soils, greatly reducing arsenic leachability compared to the untreated soils. However, SPLP and TCLP sequential leaching experiment results showed that the effectiveness of each treatment solution varies. Treatment with the FS solution produced the best effect in terms of SPLP leaching, while treatment with FS+PM+CC was most effective when the soils were subjected to TCLP leaching.

Although soils treated with solutions containing potassium permanganate showed lower arsenic mobility than those treated with only ferrous sulfate for aggressive TCLP sequential leaching, potassium permanganate treatments actually left large portions of the soil arsenic vulnerable to environmental leaching simulated using SPLP fluid. Consequently, treatment of arsenic-contaminated soil with the solution containing only ferrous sulfate is considered optimal. Compared to conventional remediation methods, in situ chemical fixation provides a cost-effective alternative for the remediation of arseniccontaminated soil in subsurface environment.

\section{Acknowledgement}

This work was funded by Southern Company and Electric Power Research Institute. The authors would like to thank Betsy Graham in the University of Alabama for her assistant in ICP-AES analyses of the studied samples and the reviews of two anonymous reviewers to improve this manuscript. 


\section{References}

Acar YB, Gale RJ. Electrokinetic remediation: basics and technology status. J Hazard Mater 1995;40:117-37.

ATSDR. Toxicological Profile for Arsenic. Atlanta, GA: U.S. Department of Health and Human Services, Public Health Service, Agency for Toxic Substances and Disease Registry; 2000.

Belzile N, Tessier A. Interactions between arsenic and iron oxyhydroxides in lacustrine sediments. Geochim Cosmochim Acta 1990;54:103-9.

Chen M, Ma LQ, HarrisWG. Baseline concentrations of 15 trace elements in Florida surface soils. J Environ Qual 1999;28:1173-81.

Cheng RC, Liang S, Wang H, Deuhler MD. Enhanced coagulation for arsenic removal. J AWWA 1994;86:79-90.

Cullen WR, Reimer KJ. Arsenic speciation in the environment. Chem Rev 1989;89:713-64.

Dragun J, Chiasson A. Elements in North American soils. Greenbelt, MD: Hazardous Materials Control Resources Institute; 1991.

Edwards M. Chemistry of arsenic removal during coagulation and Fe-Mn oxidation. J AWWA 1994;86:64-78.

Elkhatib EA, Bennett OL, Wright RJ. Arsenite sorption and desorption in soils. Soil Sci Soc Am J 1984;48:1025-30.

Emett MT, Khoe GH. Environmental stability of arsenic bearing hydrous iron oxide. In: Warren G, editor. EDP Congress; 1994. p. 153-66.

Fendorf S, Eick MJ, Grossl P, Sparks DL. Arsenate and chromate retention mechanisms on goethite. 1. surface structure. Environ Sci Technol 1997;31:315-20.

Ford RG. Rates of hydrous ferric oxide crystallization and the influence on coprecipitated arsenate. Environ Sci Technol 2002;36:2459-63.

Hering JG, Chen P,Wilkie JA, Elimelech M, Liang S. Arsenic removal by ferric chloride. J AWWA 1996;88:155-67.

Hutton M. Human health concerns of lead,mercury, cadmium and arsenic. In:Hutchinson TC,MeemaKM, editors. Lead,mercury, cadmiumand arsenic in the environment. New York: JohnWiley and Sons; 1987. p. 53-68.

Krause E, EttelVA. Solubility and stability of scorodite, FeAsO4 ${ }^{\circ}-2 \mathrm{H} 2 \mathrm{O}$ : new data and further discussion. Am Mineral 1988;73:850-4.

Kuhlmeier PD. Partitioning of arsenic species in fine-grained soils. J Air Waste Manag Assoc 1996;47:481-90.

Kuhlmeier PD. Sorption and desorption of arsenic from sandy soils: column studies. J Soil Contam 1997;6:21-36.

Manceau A. The mechanism of anion adsorption on iron oxides: evidence for the bonding of arsenate tetrahedral on free $\mathrm{Fe}(\mathrm{O}, \mathrm{OH}) 6$ edges. Geochim Cosmochim Acta 1995;59:3647-53.

Manning BA, Fendorf SE, Goldberg S. Surface structures and stability of arsenic(III) on goethite: spectroscopic evidence for inner-sphere complexes. Environ Sci Technol 1998;32:2383-8.

Moore TJ, Rightmire CM, Vempati RK. Ferrous iron treatment of soils contaminated with arseniccontaining wood-preserving solution. Soil Sediment Contam 2000;9:375-405. 
Mulligan CN, Yong RN, Gibbs BF. Remediation technologies for metal-contaminated soils and groundwater: an evaluation. Engineer Geol 2001a;60:193-207.

Mulligan CN, Yong RN, Gibbs BF. Surfactant-enhanced remediation of contaminated soil: a review. Eng Geol 2001b;60:371-80.

Paige CR, SnodgrassWJ, Nicholson RV, Scharer JM. An arsenate effect on ferrihydrite dissolution kinetics under acidic oxic conditions. Water Res 1997;31:2370-82.

Pamukcu S, Wittle JK. Electrokinetic removal of selected heavy metals from soil. Environ Prog 1992;11:241-50.

Peters RW, Miller G, Brewster MD. Desorption of arsenic from contaminated soils using chelant extraction: batch feasibility studies. Conference proceedings of emerging technologies in hazardous waste management VI. Atlanta, GA: American Chemical Society; 1994. p. 429-32.

Peterson PJ, Benson LM, Zieve R. Metalloids. In: Lepp NW, editor Effect of heavy metal pollution on plants, vol. I. Effects of Trace Metals on Plant Function; 1981.

Probstein RF, Hicks RE. Removal of contaminants from soils by electric fields. Science 1993;260:498504.

Robins RG, Huang JCY, Nishimura T, Khoe GH. The adsorption of arsenate ion by ferric hydroxide. In: Reddy RG, Hendrix JL, Queneau PB, editors. Arsenic metallurgy fundamentals and applications. Warrendale PA: TMS; 1987. p. 99-112.

Robins RG, Wong P, Nishimura T, Khoe GH, Huang J. Basic ferric arsenate: non existent. In: Hager JP, editor. EDS Congress 1992.

Warrendale PA: TMS; 1992. p. 31-9.

Sakata M. Relationship between adsorption of arsenic (III) and boron by soil and soil properties. Environ Sci Technol 1987;21:1126-30.

Shacklette HT, Boerngen JG. Element concentrations in soils and other surficial materials of the conterminous United States. US Geol Surv Prof Pap 1984:1270.

Shapiro AP, Probstein RF. Removal of contaminants from saturated clay by electroosmosis. Environ Sci Technol 1993;27:283-91.

Tanaka T. Distribution of arsenic in the natural environment with an emphasis on rocks and soils. Appl Organomet Chem 1988;2:283-95.

USEPA. Method 1311: toxicity characteristic leaching procedure. Test methods for evaluating solid waste, physical/chemical methods. 3rd ed. Washington, DC: U.S. Environmental Protection Agency, Office of Solid Waste. U.S. Government Printing Office; 1992.

USEPA. Method 1312: synthetic precipitation leaching procedure. Test methods for evaluating solid waste, physical/chemical methods. 3rd ed. Washington, DC: U.S. Environmental Protection Agency, Office of Solid Waste. U.S. Government Printing Office; 1994a.

USEPA. Method 3051: micro-wave assisted acid digestion of sediments, sludges, soils and oils. Test methods for evaluating solid waste, physical/chemical methods. 3rd ed. U.S. Environmental Protection Agency, Office of Solid Waste. U.S.; 1994b USEPA. http://www.epa.gov/safewater/arsenic/regulations.html; 2001 (accessed June 2005).

Voigot DE, Brantley SL, Hennet RJC. Chemical fixation of arsenic in contaminated soils. Appl Geochem 1996;11:633-43.

Waychunas GA, Rea BA, Fuller CC, Davis JA. Surface chemistry of ferrihydrite: part 1. EXAFS studies 
of the geometry of coprecipitate and adsorbed arsenate. Geochim Cosmochim Acta 1993;57:2251-69.

WenzelWW,Kirchbaumer N, Prohaska T, StingederG, Lombi E, Adriano DC. Arsenic fractionation in soils using an improved sequential extraction procedure. Anal Chim Acta 2001;436:309-23.

Yang L, Donahoe RJ. The form, distribution and mobility of arsenic in soils contaminated by arsenic trioxide, at sites in Southeast USA. Appl Geochem 2007;22:320-41. 